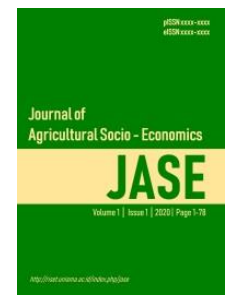

\title{
Efisiensi Saluran Pemasaran Bunga Pacar Air (Impatiens Balsamina L.) di Desa Dukuh Klopo Kecamatan Peterongan Kabupaten Jombang
}

\author{
Winarti*, Dyah Ayu Sri Hartanti, Siti Nur Qomariyah \\ Universitas KH. A Wahab Hasbullah, Jombang, Indonesia \\ *E-mail: winatn25@gmail.com
}

\begin{abstract}
The purpose of this study is to evaluate the marketing channel for water henna flowers. The marketing margin, the price received by the farmer or farmer's share, profit, and cost all contribute to the henna plant's marketing efficiency. The second purpose is to determine the price transmission elasticity. The study was conducted in the village of Dukuh Klopo, Peterongan District, Jombang Regency. The survey was place between February and April 2021 and included a total of 34 participants: 21 farmers, three collectors, and ten retailers. The survey method was employed for the investigation. Cost analysis, marketing margin and profit, marketing efficiency, and price transmission elasticity are all used in data analysis. In Dukuh Klopo Village, Peterongan District, Jombang Regency, there are two marketing channels for water henna flowers. The first channel comprises of farmers, retailers, and consumers. The second channel consists of farmers, collectors, retailers, and consumers. According to the findings of the research on the efficiency of the water henna flower marketing channel, the second marketing channel is the most efficient, with a value of 0.02 percent.
\end{abstract}

Keywords: water lover's flower; marketing effectiveness; marketing channel

Abstrak. Penelitian ini bertujuan untuk meganalisis efisiensi saluran pemasaran bunga pacar air. Margin pemasaran, harga yang diterima petani atau produsen bunga pacar air atau farmer's share, keuntungan dan biaya menentukan efisiensi pemasaran tanaman pacar air. Tujuan kedua untuk menganalisis elastisitas transmisi harga. Penelitian dilakukan di Desa Dukuh Klopo Kecamatan Peterongan Kabupaten Jombang. Penelitian dilakukan pada bulan Februari 2021 sampai dengan April 2021 dengan jumlah sampel 34 yang terdiri dari 21 petani, 3 pedagang pengepul, dan 10 pedagang pengecer. Metode penelitian yang digunakan yaitu metode survey. Analisis data menggunakan analisis biaya, margin dan keuntungan pemasaran, efisiensi pemasaran, dan elastisitas transmisi harga. Saluran pemasaran bunga pacar air di Desa Dukuh Klopo kecamatan Peterongan Kabupaten Jombang terdapat II saluran pemasaran, saluran satu terdiri dari: petani $\rightarrow$ pedagang pengecer $\rightarrow$ konsumen, dan saluran kedua terdiri dari: petani $\rightarrow$ pedagang pengepul $\rightarrow$ pedagang pengecer $\rightarrow$ konsumen. Dari hasil penelitian efisiensi saluran pemasaran bunga pacar air yang paling efisien adalah saluan pemasaran kedua dengan nilai $0,02 \%$.

Kata Kunci: bunga pacar air; efisiensi pemasaran; saluran pemasaran

\section{PENDAHULUAN}

Pertanian adalah kegiatan pemanfaatan sumber daya hayati yang dilakukan manusia untuk menghasilkan bahan pangan, bahan baku industri, atau sumber energi, serta untuk mengelola lingkungan hidupnya. Sektor pertanian merupakan sektor yang mempunyai peranan strategis dalam struktur pembangunan perekonomian nasional. Kabupaten Jombang merupakan daerah yang mempunyai produktivitas hasil pertanian yang sangat tinggi. Beberapa jenis hasil pertanian yang unggul adalah jenis makanan pokok seperti padi, jagung, dan beberapa jenis tanaman holtikultura.

Beberapa tanaman dapat dijadikan sebagai obat tradisional untuk mengobati penyakit. Obat tradisional telah lama dikenal di indonesia secara turun temurun dan digunakan masyarakat untuk memenuhi kebutuhan kesehatan dengan memanfaatkan potensi alam, baik berupa tumbuh-tumbuhan atau hewan (Suriawira, 2009) dalam (Naitullah \& Jamin, 2014). Adapula jenis tanaman hias yang 
dapat berpotensi sebagai salah satu komoditas pertanian yang cukup baik. Salah satu jenis tanaman yang berpotensi untuk usaha tani dalam meningkatkan pendapatan para petani yaitu bunga pacar air (Impatiens balsamina). Penduduk Indonesia biasanya menggunakan tanaman ini sebagai tanaman hias, namun ternyata tanaman ini mempunyai banyak manfaat dibidang kesehatan, baik dari biji, bunga, daun, maupun akarnya (Hariana Arief, 2013).

Pemasaran merupakan suatu kegiatan yang diarahkan untuk memenuhi kebutuhan melalui proses pertukaran. Saluran pemasaran merupakan serangkaian organisasi. Saluran pemasaran dapat dibedakan menurut jumlah dan tingakatannya (panjang dan pendek saluran pemasaran). Saluran pemasaran tersebut dipengaruhi oleh skala produksi dari produk yang dipasarkan (Domiah, 2016). Produk yang dihasilkan dapat terjual atau dibeli oleh konsumen akhir dengan tingkat harga yang memberikan keuntungan perusahaan jangka panjang (Assauri, 2013). Sistem pemasaran diharapkan dapat memberi informasi pasar yang baik terhadap petani, sehingga petani termotivasi untuk menghasilkan produk yang berkualitas sesuai dengan keinginan konsumen serta dapat meningkatkan pendapatan dan kesehjateraan petani. Dengan memberi informasi pasar dan sistem pemasaran yang baik akan menjadikan pemasaran bunga pacar air lebih efesien bagi semua pihak atau lembaga yang terlibat dalam penyaluran bunga pacar air ke tangan konsumen.

Selama ini budidaya atau produsen bunga pacar air tidak mengetahui secara pasti berapa keuntungan yang didapat setiap penjualan bunga pacar air, terjadi tawar menawar yang kuat diantara pedagang yang akan mempengaruhi margin di tingkat pedagang maupun pembudidaya atau produsen. Besarnya margin pemasaran, harga yang diterima pembudidaya atau produsen bunga pacar air atau farmer's share, keuntungan dan biaya akan menentukan efisiensi pemasaran bunga pacar air dan elastisitas transmisi harga, oleh karena itu diperlukan penelitian untuk mengetahui efisiensi saluran pemasaran dan elastisitas transmisi harga bunga pacar air di Desa Dukuh Klopo Kecamatan Peterongan Kabupaten Jombang.

\section{METODE}

\subsection{Lokasi dan Waktu Penelitian}

Penelitian ini dilaksanakan di Desa Dukuh Klopo Kecamatan Peterongan Kabupaten Jombang pada bulan Februari 2021 sampai April 2021. Penentuan lokasi penelitian dilakukan secara purposive berdasarkan daerah dukuh klopo adalah salah satu sentra budidaya tanaman pacar air.

\subsection{Jenis dan Sumber Data}

Data yang diperoleh dalam penelitian ini terdiri dari data primer dan sekunder. Data primer diperoleh dengan melakukan wawancara langsung dengan petani bunga pacar air (Impatiens balsamina). Data sekunder diperoleh dari data yang bersumber dari beberapa petani terkait, internet, dan informasi lainnya yang berkaitan dengan penelitian bunga pacar air (Impatiens balsamina).

\subsection{Metode Penentuan Responden}

Metode dasar yang digunakan dalam penelitian menggunakan survei dengan sensus. Seluruh populasi dijadikan sampel dalam penelitian dengan jumlah pengepul tanaman pacar air (Impatiens balsamina), serta konsumen yang membeli bunga pacar air 34 orang. Penentuan sampel dengan melakukan observasi saluran pemasaran dari produsen sampai konsumen akhir berdasarkan informasi yang diberikan petani bunga pacar air. Selanjutnya dilakukan wawancara yang berpedoman pada daftar kuisioner yang disiapkan sebagai panduan dalam pengambilan data di lapangan untuk menjawab semua tujuan penelitian (Fitria, 2013).

\subsection{Analisis Data}

Pengelolaan dan analisis data yang digunakan dalam penelitian saluran pemasaran ini berupa analisis kuantitatif dan kualitatif berdasarkan data primer dan data sekunder yang diperoleh dari hasil penelitian yang telah dilaksanakan (Sugiyono, 2017). Analisis kualitatif diuraikan secara deskriptif untuk mengetahui pola saluran pemasaran bunga pacar air di Desa Dukuh Klopo. Analisis kuantitatif dilakukan untuk mengetahui biaya, margin, keuntungan pemasaran, efisiensi pemasaran dan elastisitas transmisi harga.

Biaya pemasaran dapat dihitung dengan menggunakan rumus:

$$
\mathrm{Bp}=\mathrm{Bp} 1+\mathrm{Bp} 2+\mathrm{Bp} 3+\ldots .+\mathrm{Bpn}
$$


Dimana :

Bp

Bp1, Bp2, Bp3, .., Bpn pemasaran
= Biaya pemasaran

= Biaya pemasaran berdasarkan salura pemasaran atau tempat

Menurut (Astuti \& Dwi, 2007) Margin pemasaran, dapat dihitung menggunkan rumus:

Dimana :

$$
\mathrm{Mm}=\mathrm{Pe}-\mathrm{Pf}
$$

$\mathrm{Mm} \quad=$ margin pemasaran di tingkat petani

$\mathrm{Pe} \quad=$ harga di tingkat kelembagaan pemasaran tujuan pemasaran dari petani

Pf $\quad=$ harga di tingkat petani

Menurut (Surni, 2015) dalam (Mutmainnah, 2019) Keuntungan pemasaran dapat dihitung menggunakan rumus :

$$
\pi=\mathrm{M}-\mathrm{B}
$$

Dimana :

$\Pi \quad=$ Keuntungan $(\mathrm{Rp} / \mathrm{kg})$

$\mathrm{M} \quad=$ Marginpemasaran $(\mathrm{Rp} / \mathrm{kg})$

$\mathrm{B} \quad=$ Biaya pemasaran $(\mathrm{Rp} / \mathrm{kg})$

Efisiensi pemasaran adalah hasil total biaya pemasaran dengan total produksi yang dipasarkan dapat dihitung dengan rumus (Menurut Roesmawaty, 2011) dalam (Ratnasari et al., 2014):

$$
\mathrm{EP}=\mathrm{TB} / \mathrm{TNP} \times 100 \%
$$

Keterangan :

$\mathrm{EP} \quad=$ Efisiensi pemasaran $(\%)$

$\mathrm{TB}=$ Total biaya pemasaran $(\mathrm{Rp})$

$\mathrm{TNP}=$ Total Nilai Produk (Rp)

Kaidah keputusan pada efisiensi pemasaran ini adalah :

$0-33 \%=$ Efisien

$34-67 \%=$ Kurang Efisien

$68-100 \%=$ Tidak Efisien

Untuk menghitung elastisitas transmisi di gunakan rumus :

$$
\mathrm{Et}=\Delta \mathrm{Pr} / \Delta \mathrm{Pf} \times \mathrm{Pf} / \mathrm{Pr}
$$

Keterangan :

Et = Elastisitas Transmisi Harga

$\Delta \mathrm{Pr} \quad=$ Perubahan Harga di tingkat pengecer $(\Delta \mathrm{Rp} / \Delta \mathrm{Kg})$

$\Delta \mathrm{Pf}=$ Perubahan Harga di tingkat petani $(\Delta \mathrm{Rp} / \Delta \mathrm{Kg})$

Pf = Harga Tingkat Petani $(\Delta \mathrm{Rp} / \Delta \mathrm{Kg})$

$\operatorname{Pr} \quad=$ Harga Tingkat Pengecer $(\Delta \mathrm{Rp} / \Delta \mathrm{Kg})$

(Sudiyono, 2004 dalam (Mila Rahmi, 2019)

\section{HASIL DAN PEMBAHASAN}

\subsection{Analisis Pendapatan}

Pola saluran pemasaran

Tipe Saluran Pemasaran I (pranata agama, 2015) dalam (Kai et al., 2016).

Petani $\rightarrow$ Pengecer $\rightarrow$ Konsumen

Tipe Saluran Pemasaran II (pranata agama, 2015) dalam (Kai et al., 2016).

Petani $\rightarrow$ Pedagang Pengepul $\rightarrow$ Pengecer $\rightarrow$ Konsumen .

Berdasarkan hasil pengamatan distribusi pemasaran bunga pacar air pola saluran pemasaran I pedagang pengecer membeli bunga pacar air langsung kepada pihak petani, kemudian pedagang pengecer menjual atau memasarkannya di pasar tradisional sekitar Kecamatan Jombang, lalu pedagang pengecer menjualnya ke konsumen akhir. Saluran pemasaran pertama ini terdapat 15 petani dan 5 pedagang pengecer. Pedagang pengecer membeli bunga pacar air dari petani dengan harga Rp. 
21.067/kg dan menjual kepada konsumen akhir dengan harga Rp. 47.000/kg. Adapun pola saluran pemasaran II, petani langsung menjual hasil produksinya kepada pedagang pengepul. Responden yang diambil pada saluran pemasaran II adalah 6 orang petani dan 3 orang pedagang pengepul atau sekitar 9,7\% dari total keseluruhan sampel dalam penelitian ini. Pedagang pengepul membeli hasil panen petani secara langsung kepada petani dengan. harga Rp. 17.000,-. Harga ini disesuaikan dengan kualitas dari hasil panen tanaman pacar air. Pedagang pengepul menjual bunga pacar air ke pengecer dengan harga Rp. 27.000,-, sedangkan pedagang pengecer menjual ke konsumen akhir dengan harga Rp. 46.000,- Margin, Biaya dan Keuntungan Pemasaran.

Distribusi margin keuntungan dapat dilihat pada tabel 1.

Tabel 1. Hasil Perhitungan Margin, Biaya dan Keuntungan Pemasaran Bunga Pacar Air

\begin{tabular}{llcc}
\hline No & $\begin{array}{c}\text { Lembaga dan Komponen Biaya } \\
\text { Pemasaran }\end{array}$ & Nilai $(\mathbf{R p} / \mathbf{K g})$ & Share Margin $(\%)$ \\
\hline \multirow{2}{*}{ 1. } & Saluran I & & \\
& Harga Jual Petani & 21.067 & 0,44 \\
& Total Biaya : & 2.500 & 0,05 \\
& Transport & 2.000 & 0,04 \\
Kresek Besar & 500 & 0,01 \\
2. & Harga Beli Pengecer & 23.567 & 0,50 \\
& Biaya Pemasaran Pengecer & 182 & 0,003 \\
Kresek Kecil & 182 & 0,003 \\
Total Biaya & 23.251 & 0,99 \\
& Keuntungan Pemasaran & 23.433 & 1,0 \\
Margin & 47.000 & - \\
Harga Jual Pedagang Pengecer & 47.000 & - \\
\hline Harga Beli Konsumen & 23.433 & 100 \\
\hline
\end{tabular}

Berdasarkan tabel 1 dapat ketahui pada saluran pemasaran pertama, petani melalui satu lembaga pemasaran dalam memasarkan hasil usaha taninya langsung kepada pedagang pengecer sebelum hasil usaha taninya diterima oleh konsumen. Dilihat dari saluran pertama harga bunga pacar air di tingkat petani sebesar Rp. $21.067 / \mathrm{kg}$ dengan share margin $0,44 \%$ dari harga konsumen, dengan biaya tataniaga yang dikeluarkan sebesar Rp.2.500/kg dengan share margin $0,05 \%$. Harga beli pedagang pengecer dari petani sebesar Rp. $23.567 / \mathrm{kg}$ dengan share margin $0,50 \%$, pedagang pengecer memperoleh keuntungan sebesar Rp. 23.251/kg atau share margin keuntungannya sebesar 0,99\%, dengan biaya tataniaga yang dikeluarkan lembaga ini sebesar Rp.182/kg dengan share margin biaya tataniaga sebesar $0,003 \%$. Pada saluran pemasaran pertama petani menjual ke pedagang pengecer, sehingga biaya dan keuntungan lembaga pemasaran bisa diperoleh petani.

Tabel 2. Hasil Perhitungan Margin, Biaya dan Keuntungan Pemasaran Bunga Pacar Air (Saluran II)

\begin{tabular}{llcc}
\hline No & Lembaga dan Komponen Biaya emasaran & Nilai $(\mathbf{R p} / \mathbf{K g})$ & Share Margin $(\boldsymbol{\%})$ \\
\hline \multirow{2}{*}{ Saluran II } & & \\
& Harga Jual Petani & 17.000 & \\
$\mathbf{2} . \quad$ Biaya kresek besar & 500 & 0,38 \\
& Harga Beli pengepul & 17.500 & \\
& Biaya Pemasaran pengepul & & \\
& Transport & 284 & 0,006 \\
& Total Biaya & 284 & 0,6 \\
& Harga Jual Pedagang Pengepul & 27.000 & 0,2 \\
& Keuntungan Pemasaran & 9.216 & 0,20 \\
& Margin & 9.500 & 0,6 \\
$\mathbf{3}$ & Biaya pemasaran Pengecer & & 0,005 \\
& Harga beli & 27.000 & 0,006 \\
& Transport & 270 & 0,01 \\
& Kresek Kecil & 260 & 1,6 \\
& Total Biaya & 530 & 0,4 \\
& Harga Jual Pedagang Pengecer & 46.000 & 0,41 \\
& Keuntungan Pemasaran & 18.470 & 100 \\
\hline
\end{tabular}


Berdasarkan Tabel 2 Menunjukkan bahwa saluran pemasaran II terdapat dua lembaga pemasaran yaitu pedagang pengepul, dan pedagang pengecer. Dari alur saluran pemasaran II terlihat harga jual bunga pacar air di tingkat petani sebesar Rp.17.500/kg. Harga yang diterima petani share margin sebesar $0,38 \%$ dari harga konsumen. Total biaya untuk membeli bunga pacar air dari petani oleh pengepul mengeluarkan biaya transportasi sebesar Rp 284/kg dengan share margin sebesar $0,006 \%$. Pedagang pengepul memperoleh keuntungan sebesar Rp $27.000 / \mathrm{kg}$ dengan share margin $0,6 \%$, sedangkan pedagang pengecer membeli dari pedagang pengepul sebesar Rp. $27.000 / \mathrm{kg}$ dengan total biaya transportasi dan kresek kecil sebesar Rp.530/kg, pedagang $\mathrm{p}$

\subsection{Efisiensi Saluran Pemasaran}

Untuk mengetahui tingkat efisiensi pemasaran bunga pacar air didaerah penelitian maka dapat dilihat pada tabel dibawah ini:

Tabel 3. Efisiensi Pemasaran bunga pacar air

\begin{tabular}{ll}
\hline \multicolumn{1}{c}{ Saluran Pemasaran } & \multicolumn{1}{c}{ Biaya Pemasaran (EP) } \\
\hline Saluran Pemasaran 1 & $(2.682: 47.000) \times 100 \%$ \\
& $0,06 \times 100 \%$ \\
Saluran Pemasaran II & $0,06 \%$ \\
& $(814: 46.000 \times 100 \%$ \\
& $0,02 \times 100 \%$ \\
$0,02 \%$ \\
\hline
\end{tabular}

Berdasarkan tabel nilai efisiensi saluran pemasaran I sebesar 0,06 \% <33\% artinya saluran pemasaran I merupakan saluran pemasaran yang efisien. Nilai efisiensi saluran pemasaran II sebesar $0,02 \%$ < $33 \%$ artinya saluran pemasaran II merupakan saluran pemasaran yang efisien. Saluran II lebih efisien hal ini disebabkan, karena pengepul membeli ke petani secara langsung serta biaya pemasarnya lebih rendah sebesar Rp.814 dan pedagang pengecer mendapat harga lebih murah

\subsection{Analisis Elastisitas Transmisi Harga}

Menurut Sudiyono (2004) dalam (Mila Rahmi, 2019) elastisitas transmisi merupakan perbandingan perubahan nisbi dari harga di tingkat pengecer dengan perubahan harga di tingkat petani.

Tabel 4. Elastisitas Tansmisi Harga

\begin{tabular}{ccc}
\hline & Saluran I & Saluran II \\
\hline Pf & 23.567 & 17.500 \\
Pr & 47.000 & 46.000 \\
DPf & 23.433 & 28.500 \\
DPr & 23.433 & 19.000 \\
\hline Elastisitas & 0,5 & 0,3 \\
\hline
\end{tabular}

Berdasarkan hasil dari tabel elastisitas transmisi harga pada saluran I sebesar 0,5\% dan saluran pemasaran II sebesar 0,3\%, hal ini menunjukkan bahwa transmisi elastisitas lebih kecil dari satu (Et < 1) yang dapat diartikan bahwa perubahan harga sebesar $1 \%$ ditigkat pengecer akan mengakibatkan perubahan harga sebesar $0,5 \%$ pada tingkat petan

\section{KESIMPULAN}

Berdasarkan hasil penelitian dapat ditarik kesimpulan, bahwa kegiatan pemasaran bunga pacar air di Desa Dukuh Klopo Kecamatan Peterongan Kabupaten Jombang memiliki dua saluran pemasaran yaitu : pola saluran pemasaran I yaitu petani $\rightarrow$ pedagang pengecer $\rightarrow$ konsumen, pola saluran pemasaran II yaitu : petani $\rightarrow$ pengepul $\rightarrow$ pedagang pengecer $\rightarrow$ konsumen. Margin pemasaran yang diperoleh berbeda-bedasetiap saluran. Efisiensi pemasaran pada saluran I sebesar $0,06 \%<33 \%$ artinya saluran pemasaran I merupakan saluran pemasaran yang efisien. Nilai efisiensi saluran pemasaran II sebesar $0,02 \%>33 \%$ artinya saluran pemasaran II merupakan saluran pemasaran yang efisien. Saluran pesaran II lebih efisien hal ini disebabkan, karena pengepul membeli ke petani secara langsung serta biaya pemasarnya lebih rendah sebesar Rp.814/kg serta pedagang pengecer mendapat harga lebih murah. elastisitas transmisi harga pada saluran I sebesar 0,5\% dan saluran pemasaran II sebesar 0,3\%, hal ini menunjukkan transmisi elastisitas lebih kecil dari satu $(\mathrm{Et}<1)$ yang dapat diartikan bahwa 
perubahan harga sebesar 1\% ditingkat pengecer akan mengakibatkan perubahan harga sebesar 0,5\% pada tingkat petani.

\section{DAFTAR PUSTAKA}

Assauri, S. (2013). Manajemen Pemasaran. Rajawali Pers.

Astuti, \& Dwi, D. R. (2007). Ekonomika Agribisnis (Muhammad Ridha (ed.)). Perpustakaan Nasional, Katalog dalam terbitan (KDT).

Domiah. (2016). Analisis Saluran dan Pemasaran Industri Perikanan Tangkap Tuna Skala Kecil di Kota Bitung. Universitas Jember.

Fitria. (2013). Efisiensi Pemasaran Kacang Tanah (Arachis hypogeae) Di Kelurahan Landaan Ulin Tengah Kecamatan Landasan Ulin Kota Banjarbaru Provinsi Kalimantan Selatan. Journal of Chemical Information and Modeling, 53(9), 1689-1699.

Hariana Arief. (2013). 262 Tumbuhan Obat dan Khasiatnya. Penebar Swadaya.

Kai, Y., Baruwadi, M., Tolinggi, W. K., Agribisnis, J., Pertanian, F., Gorontalo, U. N., Pertanian, F., \& Gorontalo, U. N. (2016). Analisis Distribusi Dan Margin Pemasaran Usahatani Kacang Tanah Di Kecamatan Pulubala Kabupaten Gorontalo. AGRINESIA : Jurnal Ilmiah Agribisnis, I(1), 71-78.

Mila Rahmi. (2019). Analisis Elastisitas Transmisi Harga Jagung Manis ( Zea mays saccharata ). Universitas Sumatera Utara.

Mutmainnah. (2019). Analisis Kinerja Saluran Pemasaran INDUSTRI TAHU DI DESA LAMBUSA Kecamatan Konda Kabupaten Konawe Selatan. In SKRIPSI (Vol. 8, Issue 5). UNIVERSITAS HALU OLEO KENDARI.

Naitullah, N., \& Jamin, F. (2014). Pengaruh Pemberian Ekstrak Etanol Daun Pacar Air ( Impatiens balsamina Linn ) Terhadap Pertumbuhan Candida albicans Secara In Vitro. Jurnal Medika Veterinaria, 8(2), 125-127.

Ratnasari, Setiadi, A., \& Agustina. (2014). Analisis Pemasaran Dan Faktor - Faktor Yang Mempengaruhi Pendapatan Pembudidayaan Bandeng (Studi Kasus di Desa Tambakbulusan Kecamatan Karangtengah Kabupaten Demak, Jawa Tengah) Marketing. Tetrahedron Letters, $55,3909$.

Sugiyono, P. D. (2017). Metode Penelitian Kuantitatif, Kualitatif, dan R\&D. Alfabeta, cv. 